\title{
Biografía
}

\section{Dr. José Manuel Quirce Morales}

Llegar a describir a una persona y su obra puede ser fácil y también difícil. Yo creo que con el Dr. Quirce suceden ambas cosas. Fácil, porque hay mucho para escoger: la persona, el profesional, su obra. Difícil, porque también hay mucho que resumir, y se puede incurrir en injusticia al no ser explícito.

Sin embargo, pienso que el intento vale la pena, por eso agradezco que se me haya solicitado esta reseña.

En la Medicina hay personas que son emblemáticas: representan esa linda profesión con lujo, con hechos significativos para la disciplina y para el país. El Dr. Quirce representa ampliamente esos conceptos.

Se educa en sus primeras letras en Costa Rica, y luego -como sucedía antes de la creación de la Escuela de Medicina de la UCR-, busca dónde prepararse profesionalmente en la carrera de medicina.

Su bachillerato lo termina en el Liceo de Costa Rica, en agosto de 1928, y en octubre de ese mismo año ingresa a la Universidad Libre de Bruselas, a la denominada "primera candidatura", con apenas 17 años. Vive en una Europa convulsa, en donde igual que en América se suceden crisis en el liberalismo y la democracia.

El fascismo asciende como tendencia política, y los movimientos masivos irrumpen en un viejo orden lesionado por la I Guerra Mundial y la Revolución Rusa.

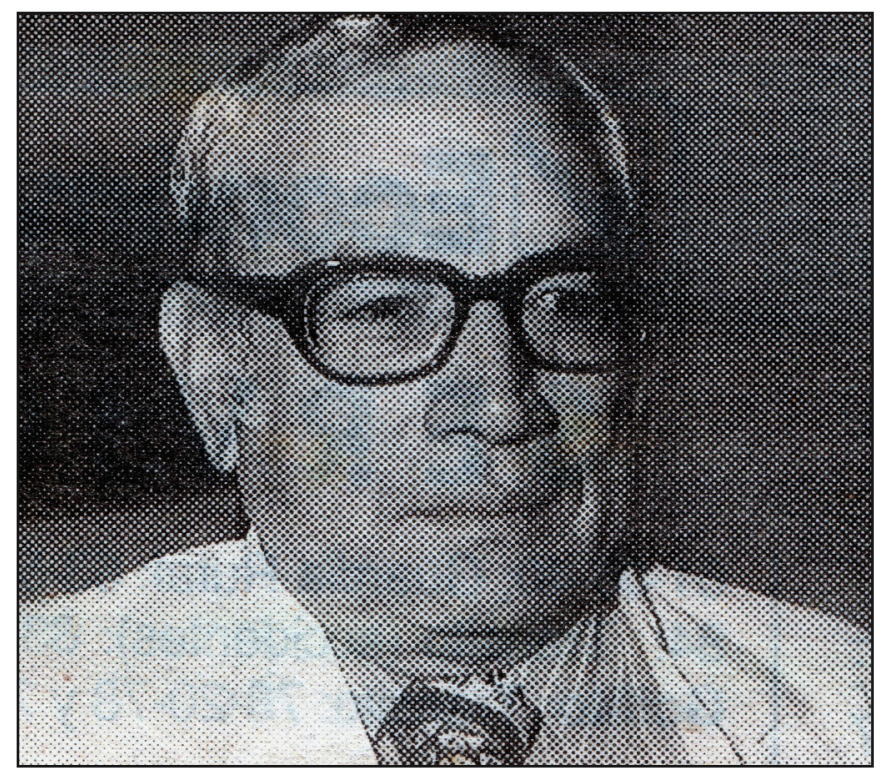

En ese proceso de depresión, Europa castiga a Alemania en muchos aspectos y este país se deja seducir por Hitler, que se convierte en dictador, convenciendo al pueblo alemán de recuperar su prestigio mundial. Hay alianza con Italia y se le brinda ayuda a Franco para fundar la II República, preludio de la II Guerra Mundial que se desata en 1938.

Es importante mencionar lo anterior, porque tales factores le deben haber ayudado al Dr. Quirce Morales, a formar su carácter en muchos aspectos.

Su carrera universitaria: en 1928 ingresa, como ya se anotó, a la "primera candidatura".

En 1929 se gradúa como "candidato al grado de doctor en medicina", de manera distinguida.

En 1933 se gradúa como "doctor en Medicina-Cirugía y Partos”, también con distinción.

Ya en 1934 se incorpora al Colegio de Médicos y Cirujanos de Costa Rica, mediante el examen de rigor, e ingresa al hospital San Juan de Dios, como "asistente meritorio".

Además de trabajar en Medicina, lo hace también en Pediatría, con un salario mensual de 75 colones. Pero, resulta interesante que se le propone el nombramiento de jefe de Medicina Infantil, y lo rechaza, ya que considera que su compañero de estudios, el Dr. Carlos Sáenz Herrera, recién llegado al país, después de hacer esa especialización en Estrasburgo (Francia), era quien debía ocupar ese puesto.

La Sección de Cirugía del Hospital San Juan de Dios incluía varias especialidades. Abarcaba Maternidad, que en 1900 se convirtió en Sección, pero también se trabajada en Ortopedia (cuyo jefe era el Dr. Fernando Pinto E., quien fue el primer becado al exterior por la Junta de Protección Social de San José), Cirugía General y otras especialidades.

Pasa luego al Servicio de Cirugía General, cuyo jefe era el Dr. Ricardo Moreno Cañas, y el de clínica, el Dr. Carlos M1. Echandi.

Al fallecer estos distinguidos médicos, asume la jefatura del servicio el Dr. Carlos Luis Valverde Vega. Después de la trágica y criminal muerte del Dr. Valverde, en 1940, se encarga de la jefatura de ese servicio mediante el respectivo concurso.

Doce años después -1952-, asume la jefatura de Sección del Departamento Quirúrgico, la cual estuvo a su cargo durante 10 años. Al terminar su ejercicio como director general, el 
Dr. Antonio Peña Chavarría, la Junta de Protección Social lo nombra director general del Hospital, cargo que ejerce hasta 1976, cuando se acoge al retiro, a los 65 años. En esa dirección, demuestra toda su capacidad gerencial y profesional.

Sus características como cirujano eran notables: cuidadoso, claro en el diagnóstico y hábil en la destreza quirúrgica. Ayudarlo a operar era un gusto, pues dentro de la amenidad de su conversación, explicaba paso por paso y la razón del procedimiento. Eso hacía que uno aprendiera de una manera que no se olvida. Y, luego, daba el seguimiento del paciente. En más de una ocasión me pedía que lo acompañara a la casa de un operado para ver su evolución. La oportunidad de colaborar con él se me brindó en varias formas: en la jefatura de Residentes e Internos del Hospital - de todas las secciones-, en la jefatura de la Consulta Externa, y en los diferentes servicios cuando asumí las jefaturas.

Brindó un gran impulso a la creación de la Unidad de Cuidados Intensivos (de ahí el nombre que esta lleva), que ha cumplido con una labor extraordinaria. Considero que fue un trabajo pionero en el país.

De igual forma, junto a otros médicos, me designa para la función de entrenar a los primeros paramédicos del país. Esto lo origina él, siendo Director del Instituto Nacional de Seguros, en 1978. Creo que explicar la eficiencia de esa idea y el campo de trabajo de estos servidores, precisa un relato aparte, por su extraordinario mérito.
Además, ocupa posiciones en la Junta Directiva del INS (1972-1976) y en la Caja Costarricense de Seguro Social (19491950).

En el gobierno del presidente Mario Echandi J., es designado Ministro de Salud, y destaca en su obra la creación del Servicio Nacional de Acueductos y Alcantarillados, elemento trascendental en la salud del país. Fue su director de 1961 a 1962.

Para seguir con sus inquietudes, acepta la Decanatura de Medicina en la Escuela de Ciencias Médicas Dr. Andrés Vesalio Guzmán, en 1990, hasta que su estado de salud se lo permitió.

En la preocupación de dotar al San Juan de Dios de mejores condiciones, y con las dificultades económicas de la época, se constituye el Comité Pro Hospital San Juan de Dios, que se da conocer con la actividad "la Marcha del Colón", integrada por personas de gran prestigio: médicos y sus esposas lograron reunir la suma de novecientos treinta mil (930 000) colones, que permitió construir el nuevo Servicio de Emergencias del Hospital.

Vemos entonces, de manera muy resumida, su actuar, sus inquietudes y realizaciones, durante una vida de trabajo guiada, sobre todo, por sus principios de ética personal y profesional.

Se puede decir, sin lugar a error, que fue un gran médico que cumplió su labor.

Dr. Edgar Cabezas Solera 